\title{
DESIGN AND OPTIMIZATION OF 6-DOF PLATFORM TOP PLATE UNDER REALISTIC JOINT CONDITIONS
}

\author{
Bhatti, U. N. ; Bashmal, S. ; Khan, S.* \& Ali, S.** \\ * King Fahd University of Petroleum \& Minerals, Dhahran, 31261, Saudi Arabia \\ ** Imam Abdulrahman bin Faisal University, Dhahran, 34212, Saudi Arabia \\ E-Mail: g201706530@kfupm.edu.sa, bashmal@kfupm.edu.sa, sikandarkhan@kfupm.edu.sa, \\ sakzada@iau.edu.sa
}

\begin{abstract}
In this work, an FEA based methodology is proposed for the accurate prediction of stiffness properties of top plate of special application 6-DOF platform. The effect of joint contact conditions on the static stiffness and natural frequency of the top plate is analysed and compared with experimental results. Top plate is first designed using a simplified finite element model where the joint contact is considered to be rigid. The design failed to meet the actual operating conditions when tested experimentally. The design is revised using actual loading conditions and introducing realistic joint contact formulation. The results obtained are in close agreement with experimental data. Based on the developed methodology, a Multi-Objective Genetic Algorithm (MOGA) based optimization study has been carried out to reach an optimum design meeting the desired performance with a minimum possible weight. Both size and shape of the top plate has been optimized and weight reduction of $5.08 \%$ has been achieved using the shape optimization. The performance parameters of final design of top plate differ by only $1.43 \%$ for static stiffness and $0.44 \%$ for modal response when compared with the experimental results.

(Received in September 2019, accepted in January 2020. This paper was with the authors 2 weeks for 1 revision.)
\end{abstract}

Key Words: Boundary Conditions, Joint Contacts, Parallel Kinematic Manipulators, Top Plate Stiffness, Optimization

\section{INTRODUCTION}

Parallel Kinematic Manipulators (PKM) have attracted the attention of many researchers in the recent past and diversified investigations have been carried out. The presence of various serial kinematic chains in these manipulators make them least affected by individual actuator positioning error [1] thus resulting in the higher stiffness, redundancy in motion and excellent load bearing capacity. These inherent properties make them an ideal candidate in various applications such as precision positioning [2,3], motion simulators, milling operations [4], coordinate measuring machines, assembly cells [5] and surgery robots [6] etc.

In most of the recent designs of the parallel platforms, the prime focus is on the development of small and energy efficient actuators [7]. The objective is to achieve high dynamical performance with minimal of excitation force and it could be done by reducing the amount of moving masses involved. This reduction can be achieved by using materials with high strength to weight ratios, use of advanced kinematical structures and minimizing the cross sections of all critical elements [6]. Li [8] has utilized non-holonomic theory to develop a four joint parallel chain manipulator that can be driven by using two motors thus reducing the actuator load.

The mechanical stiffness is an essential criterion for the precise positioning and high payload capability [9] and is defined as ability of the system to resist any significant change in its geometry under the application of external load [10]. Lower the stiffness, higher are the deformations in geometry which are undesirable as they adversely affect the performance of system by reducing the static and fatigue strength, dynamic stability, accuracy and efficiency. It becomes even critical for applications that require precise motion control with flexible links 
such as space robots [11]. The stiffness can be quantified numerically by calculating the stiffness matrix. Various techniques have been used in the literature for the evaluation of the stiffness matrix such as Finite Element Analysis (FEA) [3, 12], the Matrix Structural Analysis (MSA) [13-15] and the Virtual Joint Method (VJM) [16, 17].

FEA is the most versatile and reliable methodology among all the techniques, as it provides flexibility to model links and joints with exact shape and dimensions. Most of the FEA based studies are limited to evaluation of static stiffness of parallel platforms only, for example, Wang et al. [18] have analysed the static stiffness of 5-DOF parallel manipulator using FEA methodology and validated their simulated results experimentally using a developed prototype. Mahboub et al. [1, 19] used FEA technique for validation of a model developed for vibration analysis of hexapod table. Parameters such as mass, stiffness, damping and inertia of the hexapod's elements have been taken into account to calculate first ten natural frequencies.

Mechanical stiffness of parallel manipulators is critically affected by the stiffness of joints, which may vary during the operation, as the contact surface of joint varies [6]. In most of research work, stiffness of parallel manipulators is evaluated by considering joints as rigid with constant stiffness. However, to achieve realistic results, joint stiffness should be incorporated in the stiffness analysis by considering them as flexible elements. Ahmad et al. [6] have evaluated the effects of the spherical and universal joint stiffness on the static behaviour of a haptic device by utilizing the Hertzian contact theory. Static stiffness of a kinematic machine tool has been analysed by Bonnemains et al. [20] by taking into account the stiffness of spherical joints.

Size and shape optimization techniques are used to find the optimal structure and geometry for given design respectively [21]. The objective is to optimize thickness distribution of structural members and to find optimal shape for the design domain [22]. It is an active research area for all types of parallel manipulators. Recently evolutionary based optimization techniques such as genetic algorithms are being actively used for performance optimization of parallel manipulators [23, 24].

For the case of heavily loaded 6-DOF manipulators, such as used for large simulators and patient positioning [2], improper formulation of joint stiffness during the design phase can even lead to complete failure of system apart from error in positioning. Joint stiffness modelling also has a critical effect on final design characteristics of top plate which contribute a major share in heavily loaded platforms [25]. This application area has not been addressed in the research and is the focus of current study. The present research proposes a FEA based modelling methodology that can realistically predict the actual static and dynamic response of top plate of heavily loaded structures by incorporating the actual joint contact conditions.

In this work, a reliable stiffness modelling methodology is proposed for a special application 6-DOF platform subjected to heavy loads. Effect of joint contact conditions on both static and dynamic behaviour of platform's top plate is analysed. Finally the design of the top plate has been optimized for size and shape in order to minimize the mass in motion while guaranteeing a desired stiffness through-out a regular workspace of the mechanism. Stiffness behaviour of optimized design is compared with the available experimental test results.

\section{MODELLING AND METHODOLOGY}

A methodical procedure for analysing the overall stiffness characteristics of heavily loaded 6DOF platform's top plate under different joint contact conditions is presented in this section. The flow chart shown in Fig. 1 explains the methodology followed in the current research work. 


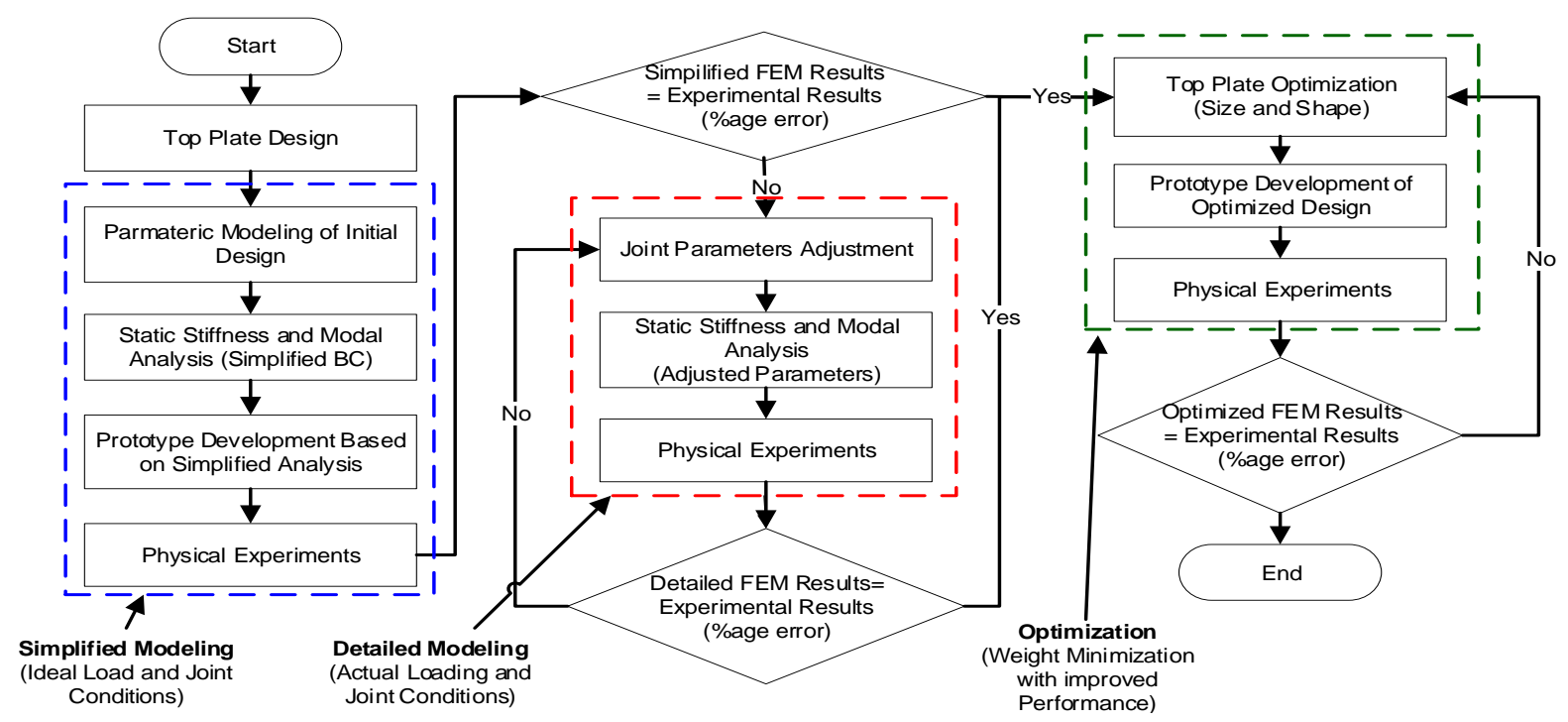

Figure 1: Methodology flow chart.

Top plate design is of prime importance if operational accuracy and safe working of such 6-DOF systems is to be ensured. The main emphasis of the proposed analysis methodology is to optimize the dynamic response of the top plate. Thus the primary objective is to design a light weight structure with maximum possible frequency.

FEA simulations using ANSYS workbench environment are performed to determine the stiffness characteristics of top plate. Pre-stress modal analysis is used to simulate the static and dynamic response of top plate. Static stiffness is measured in terms of total deformation while dynamic response is evaluated in terms of modal frequencies. Top plate material is taken as structural steel (ASTM A36). Hex dominant mesh is utilized and mapped face meshing is applied for rib structure. A mesh independence study has been conducted on the initial pre-optimized design. Based on the study, it is found that any model with mesh nodes $\geq 138,000$ and mesh elements $\geq 20,000$ is independent of mesh. Thus models for both initial and pre-optimized designs have been selected with the mesh in this range. The following sections discuss the major steps of methodology in detail.

\subsection{Top plate design}

The various design requirements of the top plate are as follows: it must withstand the payload weight of 20 ton, maximum static deflection must not exceed $4 \mathrm{~mm}$, operational frequency is $3.0 \mathrm{~Hz}$ and to ensure safe working a Factor of Safety $(F o S)$ of 3.0 is set as design criteria for modal response. Irregular hexagon shape is considered for top plate design, shown in Fig. 2 a. Three joint attachment points are located at an angle of $120^{\circ}$ along the three small sides to control the platform's 6-DOF motion. To keep the stiffness analysis simple, joint attachments with the top plate are modelled as rectangular cavities for simulating the joint contact conditions. A hollow rib patterned top plate structure is used in order to fulfil the objective of light weight design.

\subsection{Simplified modelling}

In the simplified modelling stage the contact stiffness of joints is ignored by assuming that joints are rigidly attached with the top plate. This scenario is achieved by considering the joint surfaces as rigid boundaries i.e. complete surface of joint is making contact with top plate in order to support the load. As a result all surfaces of joint cavity are modelled as fixed support. A solid modelling tool is utilized for the parametric modelling of the initial design of top plate structure. The developed top plate model with simplified joint conditions is then used for the 
FEM analysis and a preview of the mesh utilized is shown in Fig. 2 b. To simulate the effects of 20 ton task load, equivalent pressure force is applied at centre of top plate, shown in Fig. 2 c, with details given in Table I. Both static and dynamic behaviours of top plate are analysed for volume (rigid) joint contact.
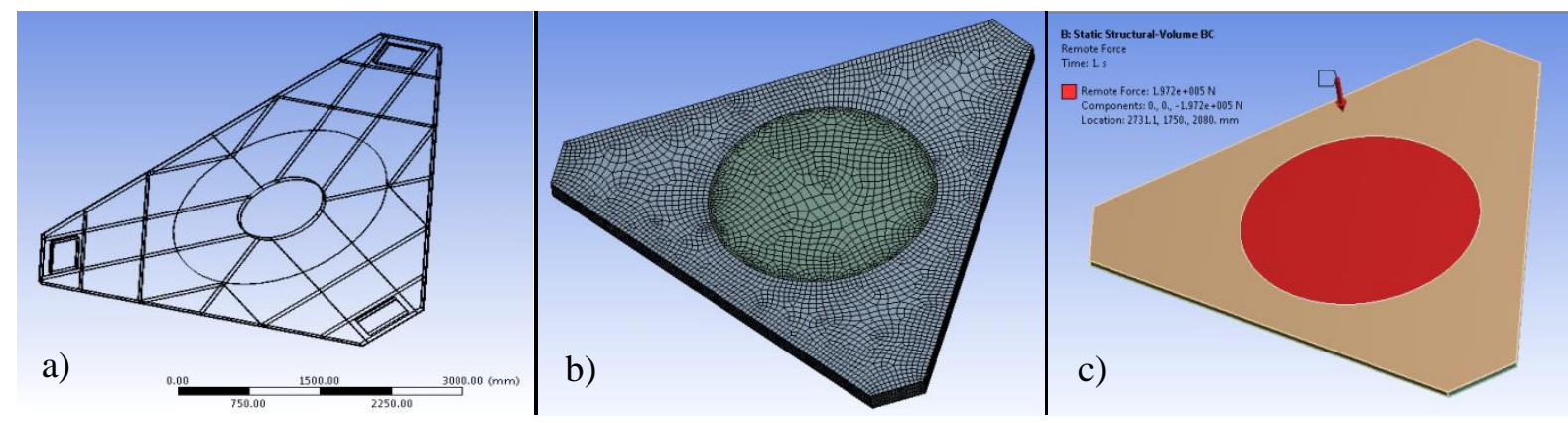

Figure 2: Initial (pre-optimized) design of top plate: a) rib structure and joint attachment points; b) preview of mesh used; c) force applied.

The governing equations for calculating the total deformation $u$ of the top plate is given by:

$$
\{u\}=[K]^{-1}\{F\}
$$

where $u$ is the displacement vector, $[K]$ is the stiffness matrix and $\{F\}$ is the equivalent load.

Eigen value problem is solved and modal frequencies, $\omega_{i}$ and corresponding mode shapes, $X_{i}(i=1,2, \ldots, 6)$, are calculated to evaluate the modal characteristics. Eq. (2) is used to calculate both parameters.

$$
\left[[K]-\omega^{2}[M]\right][X]=0
$$

where $[M]$ is the mass matrix. The modal frequencies, $\omega_{i}$ are calculated by equating determinant $(\Delta)$ of coefficient matrix to zero:

$$
\left|k_{i j}-\omega^{2} m_{i j}\right|=0
$$

Mode shapes are calculated using:

$$
[A]\{X\}=\lambda\{X\}
$$

where, $\lambda=\omega^{2}$ and $[A]=[M]^{-1}[K]$. Modal frequencies and corresponding total deformation of the structure is evaluated for the first six modes.

For validation of FEM results, the following experimental procedure is proposed:

a) Experimental model of top plate is developed based on the design using simplified modelling.

b) Top plate is assembled with the joints to complete the 6-DOF mechanism.

c) Actual loading is applied and the static deflection is noted.

d) Mechanism is tested for operating conditions to calculate the fundamental resonant frequency.

Table I: Task load specifications.

\begin{tabular}{|l|c|}
\hline Weight & 20 ton \\
\hline Diameter & $2.5 \mathrm{~m}$ \\
\hline Height & $6.0 \mathrm{~m}$ \\
\hline C.G. & $2.0 \mathrm{~m}$ from base \\
\hline Mass moment of inertias \\
\hline $\boldsymbol{I}_{x x}$ & $6.12 \times 10^{7} \mathrm{t} \cdot \mathrm{mm}^{2}$ \\
\hline $\boldsymbol{I}_{y y}$ & $2.33 \times 10^{7} \mathrm{t} \cdot \mathrm{mm}^{2}$ \\
\hline $\boldsymbol{I}_{z z}$ & $6.12 \times 10^{7} \mathrm{t} \cdot \mathrm{mm}^{2}$ \\
\hline
\end{tabular}


Physical experimental prototype is constructed to verify the results obtained through simplified FEA modelling. The deviation from the experimental results would ascertain the amount of accuracy to which the simplified model is implemented to the problem. Improvement in the procedure adopted, if any, is to be made by taking into account percentage relative error criterion. Further discussion and comparison of results are presented in section 3 .

\subsection{Detailed modelling}

In the detailed model, the contact stiffness of joints is incorporated by simulating different types of contact that joints can make with top plate. The nominal area contact and line contact conditions are proposed to calculate the contact stiffness of joints, respectively. At first, a surface and then a line of rectangular joint cavities are given as fixed support boundary condition to simulate these effects. The static and dynamic responses of top plate are analysed for each of the two joint contact conditions. Instead of applying pressure force actual load is modelled and applied on the top plate to analyse the stiffness behaviour of top plate with the task load. The details of task load modelled are given in Table I.

A similar procedure, as used for simplified modelling, is adopted to verify the detailed modelling results i.e. results from a physical experiment are correlated with the detailed analysis results to determine their accuracy. The same criterion of percentage relative error is used for this instance to find the deviation from actual results.

\subsection{Top plate optimization}

Once the correct boundary conditions have been identified and stiffness parameters of initial design of top plate have been validated using the experimental results. The structure of top plate is optimized to have desired stiffness characteristics, i.e. maximum allowable deflection of $4 \mathrm{~mm}$ and minimum $1^{\text {st }}$ modal frequency of $9 \mathrm{~Hz}$, with the minimum overall weight. For this purpose a two-step approach is proposed:

a) Size of top plate is optimized to achieve the desired static and dynamic characteristics.

b) Shape of top plate is optimized in order to have a structure with minimum possible mass while satisfying the desired stiffness requirements.

For said purpose, a goal driven optimization study on top plate has been carried out using ANSYS design exploration module and response surface optimization tool is utilized. In first phase, response surfaces of desired outputs, for variation in given input (design) parameters, are generated using Response Surface Methodology (RSM). $2^{\text {nd }}$ order polynomial method has been utilized for generation of these surfaces. In the next phase, based on generated response surfaces, Multi-Objective Genetic Algorithm (MOGA) optimization technique is employed to obtain optimum design candidates. An initial population size of 100 samples with an equal number of samples for each iteration has been used and three candidate designs have been generated. Finally, the best design meeting the desired objectives and constraints is selected.

In size optimization, the overall height and rib thickness of top plate are chosen as design variables to be optimized to achieve desired static and dynamic response of top plate under the effect of fixed task load. The minimum weight of top plate is also used as an additional objective in this step.

Once the top plate design meeting the desired performance characteristics has been achieved using size optimization, the shape of the top plate is optimized with the objective of having a structure with minimum possible weight. For this purpose the structure height at centre is kept fixed while height at outer section is optimized for weight reduction. The optimized structure thus bear desired static and dynamic behaviour but with the minimum possible mass. 
The same procedure, as adopted for simplified and detailed modelling, is adopted to verify the results of optimization. The FEM results for final optimized design are correlated with experimental results. Percentage relative error between the two values has been utilized as validation criterion for simulation results.

\section{RESULTS AND DISCUSSION}

Static stiffness results are evaluated in terms of total deformation of the top plate while the dynamic response is measured in terms of modal frequencies. The first modal frequency is of prime interest as it is the lowest frequency at which the structure would resonate when subjected to operating conditions, so the result evaluation is primarily based on checking the first modal frequency.

As the $F o S$ for the current design is set to 3.0 , it corresponds to a minimum $1^{\text {st }}$ modal frequency of $9 \mathrm{~Hz}$ while keeping the static deformation within the allowable limit of $4 \mathrm{~mm}$ for final design of structure.

\subsection{Initial design of top plate}

For initial design of top plate the free modal analysis has been conducted to determine the $1^{\text {st }}$ natural frequency of top plate while static deformation of top plate under its own weight has been calculated. The $1^{\text {st }}$ natural frequency obtained was $21.03 \mathrm{~Hz}$ which is approximately seven times the operating frequency while static total deformation was $0.76 \mathrm{~mm}$. As the results obtained from initial analysis were meeting the objectives set in terms of $F o S$, so this design was selected for further evaluation of its stiffness behaviour under loaded mode.

\subsection{Simplified modelling results}

To apply the proposed analysis methodology to the structure, a parametric model of initial design of top plate is generated according to the specifications presented in Table II.

Table II: Final specifications of designed top plate (pre-optimized).

\begin{tabular}{|l|c|}
\hline Top plate mass & $2.64 \mathrm{ton}$ \\
\hline Top plate height & $80.0 \mathrm{~mm}$ \\
\hline Upper /Lower plate \& rib thickness & $10.0 \mathrm{~mm}$ \\
\hline Length of longer side & $4460 \mathrm{~mm}$ \\
\hline Length of shorter side & $800 \mathrm{~mm}$ \\
\hline Circumscribed diameter & $7000 \mathrm{~mm}$ \\
\hline Circular rib diameter & $1000 \mathrm{~mm}$ \\
\hline Joint attachment geometry & $500 \times 300 \times 50 \mathrm{~mm}^{3}$ \\
\hline
\end{tabular}

Based on FEA analysis of top plate with simplified boundary conditions the static total deformation obtained is $4.24 \mathrm{~mm}$ and $1^{\text {st }}$ modal frequency is $4.36 \mathrm{~Hz}$. The contours for static total deformation and mode shape for first frequency are shown in Figs. $3 \mathrm{a}$ and $3 \mathrm{~b}$ respectively.

To validate the results from simplified FEM model, a physical prototype of the selected test case has been developed and tested experimentally. The static deflection at the centre of top plate, under the application of actual task load, is measured with the help of delta strain rosettes. For said purpose, strain gauges were applied at the lower surface of top plate. The mechanism is further tested for actual operating conditions and vibration data is collected using accelerometers. Frequencies have been extracted from vibration spectrum obtained from accelerometer data. Four different tests have been conducted and results for static deformation 
and $1^{\text {st }}$ modal frequency are given in Table III. The average value of these results has been taken for comparison. It was observed that the structure started to resonate when tested under realistic operating conditions with an average value of frequency of $2.92 \mathrm{~Hz}$ as compared to estimated value of $4.36 \mathrm{~Hz}$. The measured static deflection of structure was $12.98 \mathrm{~mm}$ almost three times higher than predicted value of $4.24 \mathrm{~mm}$. Therefore, the current assumption of rigid joint behaviour in the FEA modelling failed to predict the actual behaviour. A comparison of simplified FEM modelling with experimental results has been given in the first row of Table IV in the form of relative percentage error.
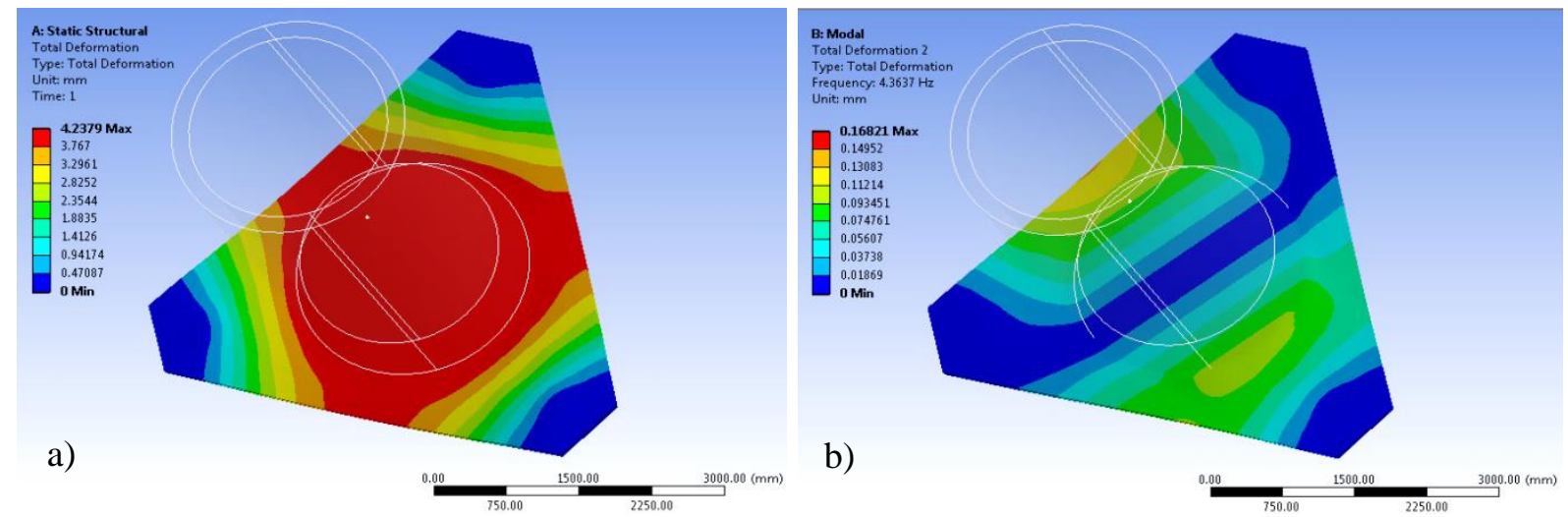

Figure 3: Simplified FEM results: a) static total deformation contours; b) mode shape for $1^{\text {st }}$ mode frequency.

The average relative error for $1^{\text {st }}$ modal frequency is $49.32 \%$ and for static deformation a value of $67.33 \%$ is obtained. The error values obtained are beyond the acceptable range of $\leq 10 \%$, which motivated the development of a more detailed model.

Table III: Experimental results for top plate (pre-optimized).

\begin{tabular}{|l|c|c|c|c|c|}
\hline Experiment No. & P1 & P2 & P3 & P4 & Avg. value \\
\hline Static $(\mathrm{mm})$ & 12.80 & 13.60 & 12.80 & 12.70 & 12.98 \\
\hline $\mathbf{1}^{\text {st }}$ modal freq. $(\mathrm{Hz})$ & 2.80 & 2.70 & 3.00 & 3.20 & 2.92 \\
\hline
\end{tabular}

\subsection{Detailed modelling results}

As part of detailed modelling an iterative procedure is adopted in which joint contact conditions are changed systematically until a desired accuracy is obtained between the FEM and experimental results.

At first an area joint contact condition is analysed. Considering the area contact between joints and top plate, the static deformation obtained is $5.04 \mathrm{~mm}$ and $1^{\text {st }}$ modal frequency is $4.20 \mathrm{~Hz}$. The area contact results when compared with rigid joint condition, as shown in Figs. $4 \mathrm{a}$ and $4 \mathrm{~b}$, show a drop in $1^{\text {st }}$ natural frequency and an increase in static total deformation moving closer to experimental values.

In order to get more accurate results another contact condition i.e. one line of joint making contact with top plate is considered. The results obtained depict a sharp increase in the static deformation from $5.04 \mathrm{~mm}$ to $12.63 \mathrm{~mm}$, Fig. 4 a, and drop in $1^{\text {st }}$ resonant frequency from $4.20 \mathrm{~Hz}$ to $3.13 \mathrm{~Hz}$, Fig. 4 b, predicting values very close to experimental results.

The results from detailed FEM modelling are compared with the average experimental results, presented in Table IV, in order to validate their accuracy in predicting the actual behaviour. The average relative error for static total deflection and $1^{\text {st }}$ modal frequency using area joint contact condition are $61.17 \%$ and $43.84 \%$ respectively. Although the results 
indicate higher accuracy compared to rigid joint contact but the relative error for this scenario is still far away from the acceptable range.

For line contact condition the relative error obtained for static deformation and $1^{\text {st }}$ modal frequency are $2.70 \%$ and $7.19 \%$ respectively. The errors for this case are within acceptable range of $\leq 10 \%$. Figs. 4 a and $4 \mathrm{~b}$ compare the average experimental value with variation of static total deformation and $1^{\text {st }}$ resonant frequency for three joint contact conditions considered. By observing these figures, it could be ratiocinated that the line contact condition gives a more realistic prediction of overall stiffness behaviour for the top plate and should be utilized while designing these types of structures.

Table IV: Relative error between the average experimental and FEM results.

\begin{tabular}{|c|c|c|c|}
\hline FEA model & Joint contact type & Static deflection & $\mathbf{1}^{\text {st }}$ modal frequency \\
\hline Simplified model & Rigid joint contact & $67.33 \%$ & $49.32 \%$ \\
\hline \multirow{2}{*}{ Detailed model } & Area joint contact & $61.17 \%$ & $43.84 \%$ \\
\cline { 2 - 4 } & Line joint contact & $2.70 \%$ & $7.19 \%$ \\
\hline
\end{tabular}
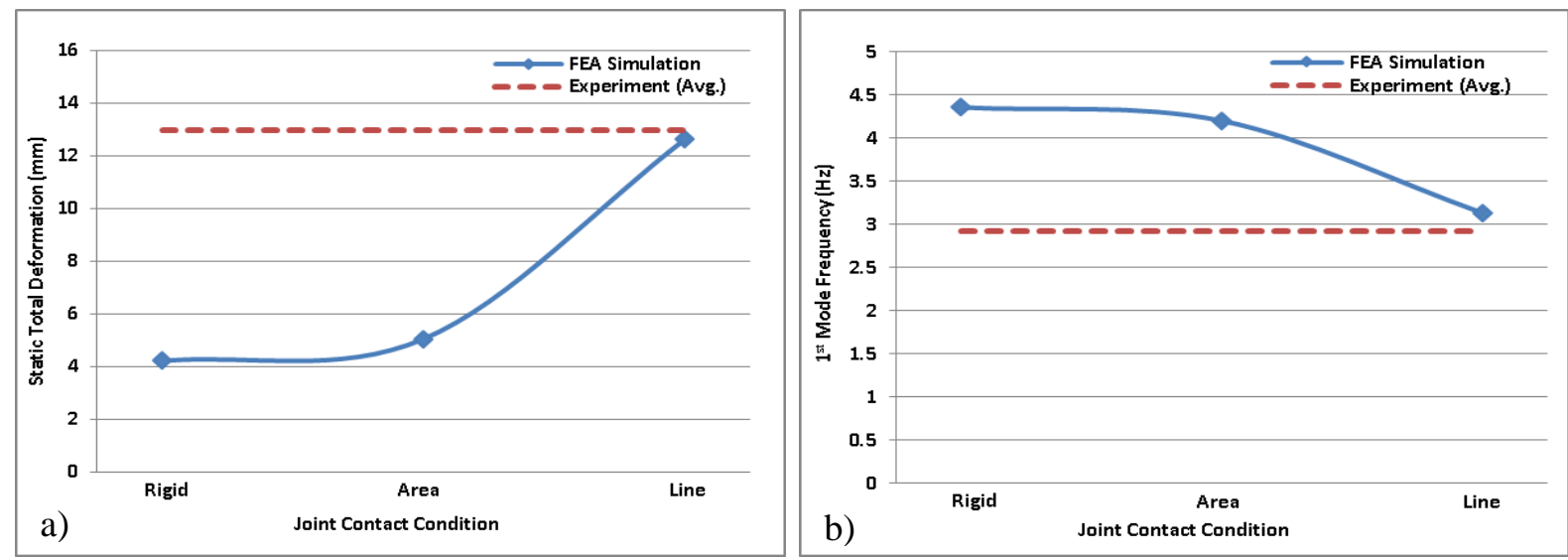

Figure 4: Variation with joint contact: a) static deformation; b) $1^{\text {st }}$ mode frequency.

\subsection{Top plate optimization}

In size optimization, the cross sectional area of ribs is optimized by altering their aspect ratio. Thus, the two design variables for the size optimization problem are rib height and rib thickness, respectively. The overall height of top plate is dependent on these two parameters and is given by:

Overall height of top plate $=$ Rib height $+2 \times$ Rib thickness

The optimization problem is formulated below.

\section{Objectives:}

\section{Constraints:}

$\begin{array}{ll}\text { Maximize } & \text { Frequency }(\mathrm{Hz}) \\ \text { Minimize } & \text { Total deformation }(\mathrm{mm}) \\ \text { Minimize } & \text { Top plate mass (ton) }\end{array}$

$$
80 \leq \mathrm{Rib} \text { height }(\mathrm{mm}) \leq 220, \quad 8 \leq \mathrm{Rib} \text { thickness }(\mathrm{mm}) \leq 16
$$

The response of $1^{\text {st }}$ modal frequency and static deformation against the design variables, for the case of size optimization, are shown in Figs. 5 a and 5 b. The resonant frequency varies almost linearly with the increase in height and thickness but is more sensitive to height of structure. The static deformation decreases exponentially with height and linearly with thickness. 
Setting the frequency maximization objective as goal, MOGA optimization method has been employed to determine the optimum design within the design space. The optimum candidate designs obtained as result of size optimization are presented in Table V. As the objective was to optimize the dynamic response of top plate so the candidate having the maximum frequency, i.e. candidate design $\mathrm{C}$, is selected as the optimum design for further analysis.

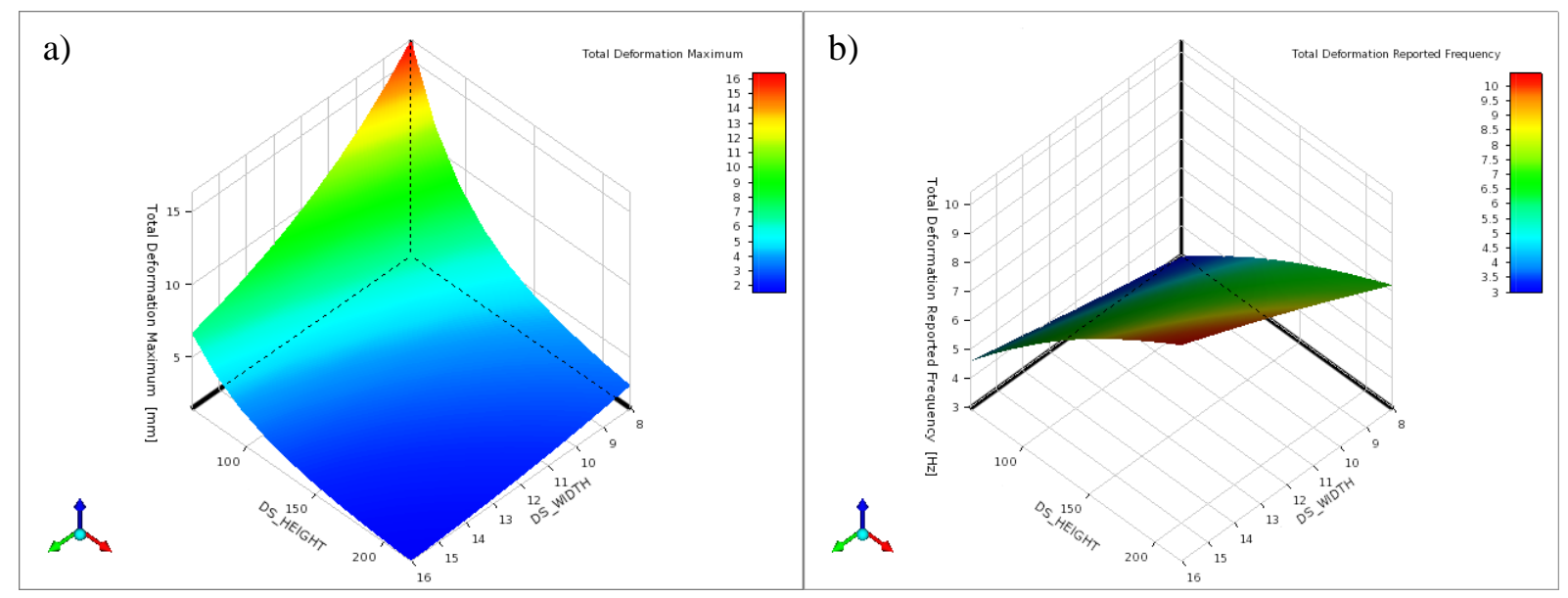

Figure 5: Response surfaces (size optimization): a) static deformation; b) $1^{\text {st }}$ mode frequency.

Table V: Optimum candidate points obtained using MOGA (size optimization).

\begin{tabular}{|c|c|c|c|c|c|}
\hline \multirow[b]{2}{*}{$\begin{array}{c}\text { Candidate } \\
\text { point }\end{array}$} & \multicolumn{2}{|c|}{ Top plate } & \multirow{2}{*}{$\begin{array}{c}\text { Static } \\
\text { deformation } \\
(\mathrm{mm})\end{array}$} & \multirow{2}{*}{$\begin{array}{c}1^{\text {st }} \text { modal } \\
\text { frequency } \\
(\mathrm{Hz})\end{array}$} & \multirow{2}{*}{$\begin{array}{c}\text { Top plate } \\
\text { mass } \\
\text { (ton) }\end{array}$} \\
\hline & $\begin{array}{c}\text { Height } \\
(\mathrm{mm})\end{array}$ & $\begin{array}{l}\text { Width } \\
(\mathrm{mm})\end{array}$ & & & \\
\hline $\mathrm{A}$ & 246 & 14 & 1.71 & 9.70 & 4.714 \\
\hline B & 238 & 14 & 1.75 & 9.56 & 4.718 \\
\hline $\mathrm{C}$ & 247 & 14 & 1.70 & 9.74 & 4.722 \\
\hline
\end{tabular}

The shape of structure is optimized, in the next stage, to achieve a lightweight structure meeting the desired stiffness characteristics set for final design. For this purpose the shape of the top plate was varied so that its height at the centre section was kept fixed while material was removed from the outer sections (Fig. 6). Optimum height of ribs for the outer section is determined using RSM and MOGA optimization. The optimization problem formulated is shown below.

\section{Objectives:}

\section{Constraints:}

$$
\text { Minimize Top plate mass (ton) }
$$

$$
\begin{aligned}
& \text { Frequency } \geq 9 \mathrm{~Hz} \\
& \text { Static total deformation } \leq 2 \mathrm{~mm} \\
& 60 \leq \text { Rib height at outer section }(\mathrm{mm}) \leq 180
\end{aligned}
$$

The optimum candidate designs obtained as results of MOGA are presented in Table VI. Candidate design $\mathrm{B}$ is selected as final optimized design of top plate as it meets the desired frequency target with minimum top plate mass. Comparison of weight of this final design with the design obtained though size optimization shows that via shape optimization the weight of top plate has been reduced from 4.72 ton to 4.48 ton. Thus a weight reduction of $5.08 \%$ has been achieved by employing the shape optimization. 
Table VI: Optimum candidate points for shape optimization using MOGA.

\begin{tabular}{|c|c|c|c|c|c|}
\hline \multirow[b]{2}{*}{$\begin{array}{c}\text { Candidate } \\
\text { point }\end{array}$} & \multicolumn{2}{|c|}{ Top plate } & \multirow[b]{2}{*}{$\begin{array}{c}\text { Static } \\
\text { deformation } \\
(\mathrm{mm})\end{array}$} & \multirow[b]{2}{*}{$\begin{array}{l}\mathbf{1}^{\text {st }} \text { modal } \\
\text { frequency } \\
\quad(\mathrm{Hz})\end{array}$} & \multirow[b]{2}{*}{$\begin{array}{c}\text { Top plate } \\
\text { mass } \\
\text { (ton) }\end{array}$} \\
\hline & $\begin{array}{c}\text { Outside } \\
\text { height } \\
(\mathrm{mm})\end{array}$ & $\begin{array}{l}\text { Width } \\
(\mathrm{mm})\end{array}$ & & & \\
\hline $\mathrm{A}$ & 201 & 14 & 1.42 & 9.00 & 4.482 \\
\hline B & 201 & 14 & 1.42 & 8.99 & 4.480 \\
\hline $\mathrm{C}$ & 200 & 14 & 1.43 & 8.94 & 4.457 \\
\hline
\end{tabular}

The parametric model of this final optimum design, shown in Fig. 6, has been developed according to specification given in Table VII and stiffness behaviour has been analysed in detail using ANSYS pre stress modal analysis. The static deflection and $1^{\text {st }}$ modal frequency obtained are $1.42 \mathrm{~mm}$ and $8.99 \mathrm{~Hz}$, respectively. Static deformation and $1^{\text {st }}$ mode shape contours of the final design of top plate are same as shown in Fig. 3.

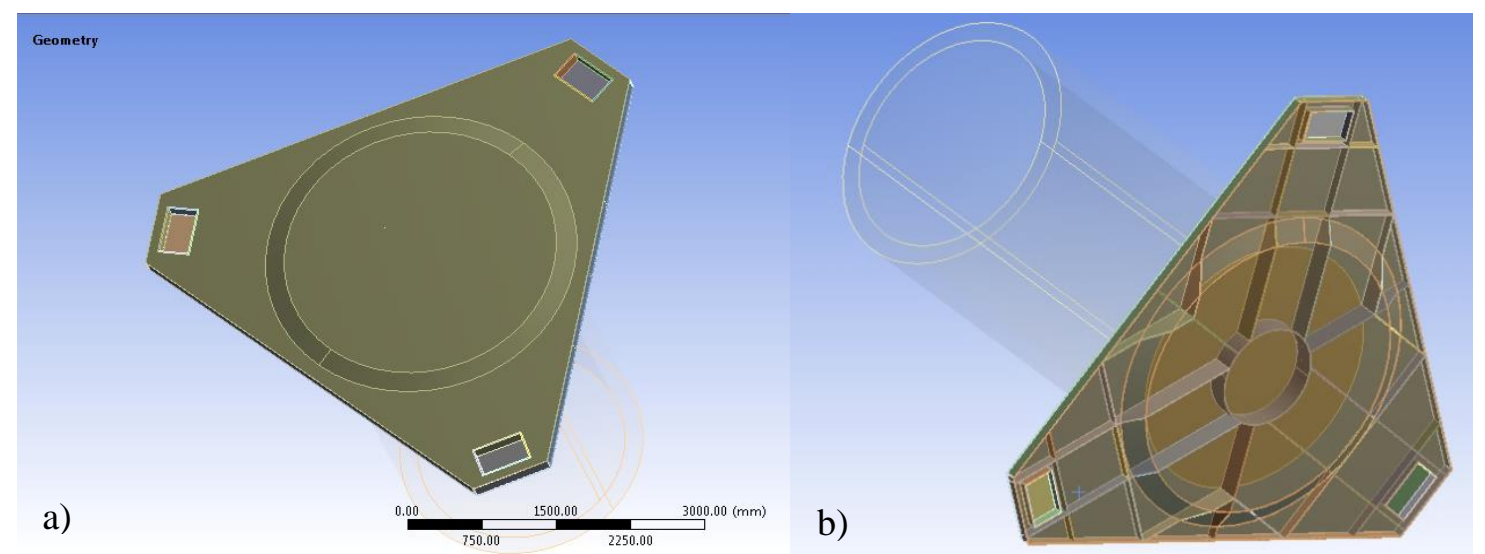

Figure 6: Final shape of optimized top plate: a) outer structure; b) rib structure.

Table VII: Specifications of final optimized design.

\begin{tabular}{|l|c|}
\hline Top plate mass & $4.48 \mathrm{ton}$ \\
\hline Top plate height at centre & $247 \mathrm{~mm}$ \\
\hline Height of outer section & $201 \mathrm{~mm}$ \\
\hline Upper/lower plate \& rib thickness & $14.0 \mathrm{~mm}$ \\
\hline Circular rib diameter & $1000 \mathrm{~mm}$ \\
\hline Joint attachment geometry & $500 \times 300 \times 160 \mathrm{~mm}^{3}$ \\
\hline
\end{tabular}

A physical model of final optimized structure has been developed and experimental testing is performed to determine the actual stiffness characteristics. The test conditions and procedure for measurement is same as described in section 3.2 for simplified modelling. The results obtained from experiment are presented in Table VIII. The average percentage error for static deflection is $1.43 \%$ and $0.44 \%$ for $1^{\text {st }}$ resonance frequency. The results obtained from final optimized FEM model and experimental design are in close agreement thus validating the proposed FEA methodology.

Table VIII: Experimental values for top plate (optimized design).

\begin{tabular}{|l|c|c|c|c|c|}
\hline Experiment No. & P1 & P2 & P3 & P4 & Avg. value \\
\hline Static $(\mathrm{mm})$ & 1.30 & 1.40 & 1.40 & 1.50 & 1.40 \\
\hline $\mathbf{1}^{\text {st }}$ modal freq. $(\mathrm{Hz})$ & 9.50 & 8.90 & 8.90 & 8.80 & 9.03 \\
\hline
\end{tabular}




\section{CONCLUSIONS}

An accurate simulation driven stiffness modelling methodology has been proposed in this work for top plate of a special application 6-DOF platform i.e. subjected to heavy loads. Both static and dynamic characteristics, in terms of total deformation and modal frequency, are analysed. The FEM results have been verified with those obtained through experimental testing. Three different joint contact scenarios have been analysed to reach a model that closely predict the actual behaviour. Analysis depicts that by taking into account the contact stiffness of joints; the average relative error between FEA and experimental results has been reduced from $49.32 \%$ to $7.19 \%$ for $1^{\text {st }}$ mode frequency and from $67.33 \%$ to $2.70 \%$ for static deflection of top plate. Thus the application of correct boundary conditions at joints play a critical role in realistic prediction of the actual behaviour of heavily loaded 6-DOF parallel platforms. At the end, MOGA based size and shape optimization technique has been used to reach an optimal design that meets the required stiffness characteristics. A weight reduction of $5.08 \%$ has been achieved through shape optimization. Final optimized design of the top plate showed very good agreement with experimental results with an average relative error of $1.43 \%$ and $0.44 \%$ for static deflection and $1^{\text {st }}$ natural frequency respectively.

\section{ACKNOWLEDGEMENT}

The authors would like to acknowledge the support of King Fahd University of Petroleum \& Minerals.

\section{REFERENCES}

[1] Mahboubkhah, M.; Nategh, M. J.; Esmaeilzadeh, K. S. (2009). A comprehensive study on the free vibration of machine tools' hexapod table, The International Journal of Advanced Manufacturing Technology, Vol. 40, No. 11-12, 1239-1251, doi:10.1007/s00170-008-1433-5

[2] Meggiolaro, M. A.; Dubowsky, S.; Mavroidis, C. (2005). Geometric and elastic error calibration of a high accuracy patient positioning system, Mechanism and Machine Theory, Vol. 40, No. 4, 415-427, doi:10.1016/j.mechmachtheory.2004.07.013

[3] Shin, H.-P.; Moon, J.-H. (2018). Static and dynamic analyses of a 6-DOF ultra-precision parallel mechanism, International Journal of Precision Engineering and Manufacturing, Vol. 19, No. 7, 1019-1026, doi:10.1007/s12541-018-0120-1

[4] Clinton, C. M.; Zhang, G.; Wavering, A. J. (1996). Stiffness modeling of a Stewart-platformbased milling machine, Transactions of NAMRI/SME, Technical Report, Institute for Systems Research, 9 pages, doi:10.6028/nist.ir.5918

[5] Meng, Q.; Xie, F.; Liu, X.-J. (2018). Conceptual design and kinematic analysis of a novel parallel robot for high-speed pick-and-place operations, Frontiers of Mechanical Engineering, Vol. 13, No. 2, 211-224, doi:10.1007/s11465-018-0471-4

[6] Ahmad, A.; Andersson, K.; Sellgren, U.; Khan, S. (2014). A stiffness modeling methodology for simulation-driven design of haptic devices, Engineering with Computers, Vol. 30, No. 1, 125141, doi:10.1007/s00366-012-0296-4

[7] Pashkevich, A.; Klimchik, A.; Chablat, D. C. (2009). Nonlinear effects in stiffness modeling of robotic manipulators, Proceedings of International Conference on Computer and Automation Technology, World Academy of Science, Engineering and Technology, 168-173

[8] Li, L. (2018). Mechanism design and motion planning of parallel-chain nonholonomic manipulator, International Journal of Simulation Modelling, Vol. 17, No. 2, 327-336, doi:10.2507/IJSIMM17(2)CO7

[9] Angeles, J.; Park, F. C. (2008). Performance evaluation and design criteria, Siciliano, B.; Khatib, O. (Eds.), Springer Handbook of Robotics, Springer, Berlin, 229-244, doi:10.1007/978-3-54030301-5_11

[10] Rivin, E. I. (2000). Stiffness and Damping in Mechanical Design, Book Review by Balachandran, B., Journal of Mechanical Design, Vol. 122, No. 1, 147, doi: $\underline{10.1115 / 1.533570}$ 
[11] Huang, X.-Q.; Tang, X.-T.; Chen, L. (2018). Simulation for trajectory tracking of multi-flexiblelink space robot with deadzone, International Journal of Simulation Modelling, Vol. 17, No. 4, 677-689, doi:10.2507/IJSIMM17(4)459

[12] Yu, G.; Wang, L.; Wu, J.; Wang, D.; Hu, C. (2018). Stiffness modeling approach for a 3-DOF parallel manipulator with consideration of nonlinear joint stiffness, Mechanism and Machine Theory, Vol. 123, 137-152, doi:10.1016/j.mechmachtheory.2018.01.005

[13] Shankar Ganesh, S.; Koteswara Rao, A. B. (2014). Stiffness of a 3-degree of freedom translational parallel kinematic machine, Frontiers of Mechanical Engineering, Vol. 9, No. 3, 233-241, doi:10.1007/s11465-014-0312-Z

[14] Klimchik, A.; Pashkevich, A.; Chablat, D. (2018). MSA-technique for stiffness modeling of manipulators with complex and hybrid structures, IFAC-PapersOnLine, Vol. 51, No. 22, 37-43, doi:10.1016/j.ifacol.2018.11.515

[15] Klimchik, A.; Pashkevich, A.; Chablat, D. (2019). Fundamentals of manipulator stiffness modeling using matrix structural analysis, Mechanism and Machine Theory, Vol. 133, 365-394, doi:10.1016/j.mechmachtheory.2018.11.023

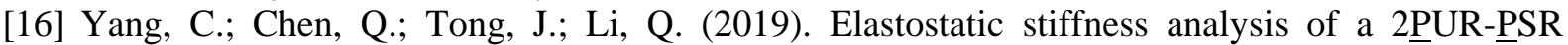
overconstrained parallel mechanism, International Journal of Precision Engineering and Manufacturing, Vol. 20, No. 7, 569-581, doi:10.1007/s12541-019-00077-1

[17] Xu, P.; Li, B.; Cheung, C.-F.; Zhang, J.-F. (2017). Stiffness modeling and optimization of a 3DOF parallel robot in a serial-parallel polishing machine, International Journal of Precision Engineering and Manufacturing, Vol. 18, No. 4, 497-507, doi:10.1007/s12541-017-0060-1

[18] Wang, Y.; Huang, T.; Zhao, X.; Mei, J. P.; Chetwynd, D. G. (2008). A semi-analytical approach for stiffness modeling of PKM by considering compliance of machine frame with complex geometry, Chinese Science Bulletin, Vol. 53, No. 16, Paper 2565, doi:10.1007/s11434-008-0298-1

[19] Mahboubkhah, M.; Nategh, M. J.; Esmaeilzade Khadem, S. (2008). Vibration analysis of machine tool's hexapod table, The International Journal of Advanced Manufacturing Technology, Vol. 38, No. 11-12, 1236-1243, doi:10.1007/s00170-007-1183-9

[20] Bonnemains, T.; Chanal, H.; Bouzgarrou, C.; Ray, P. (2008). Definition of a new static model of Parallel Kinematic Machines: Highlighting of overconstraint influence, 2008 IEEE/RSJ International Conference on Intelligent Robots and Systems, 2416-2421, doi:10.1109/ IROS.2008.4650957

[21] Bendsøe, M. P.; Sigmund, O. (2004). Topology Optimization - Theory, Methods, and Applications, $2^{\text {nd }}$ edition, Springer-Verlag, Berlin, doi:10.1007/978-3-662-05086-6

[22] Liu, X.; Li, Z.; Chen, X. (2011). Structural optimization of typical rigid links in a parallel kinematic machine, Frontiers of Mechanical Engineering, Vol. 6, No. 3, Paper 344, doi:10.1007/s11465-011-0227-x

[23] Zhang, D.; Gao, Z. (2015). Performance analysis and optimization of a five-degrees-of-freedom compliant hybrid parallel micromanipulator, Robotics and Computer-Integrated Manufacturing, Vol. 34, 20-29, doi:10.1016/j.rcim.2015.01.002

[24] Leal-Naranjo, J.-A.; Ceccarelli, M.; Torres-San-Miguel, C.-R.; Aguilar-Perez, L.-A.; Urriolagoitia-Sosa, G.; Urriolagoitia-Calderon, G. (2018). Multi-objective optimization of a parallel manipulator for the design of a prosthetic arm using genetic algorithms, Latin American Journal of Solids and Structures, Vol. 15, No. 3, 15 pages, doi:10.1590/1679-78254044

[25] Bhatti, U. N.; Khan, S.; Ali, S.; Horoub, M. M. (2018). A numerical modeling study of the effects of various joint boundary conditions on stiffness behavior of 6DOF platform's top plate, $9^{\text {th }}$ International Conference on Mechanical and Aerospace Engineering (ICMAE), 243-248, doi:10.1109/ICMAE.2018.8467631 